\title{
Predictors of Dropout by Female Obese Patients Treated with a Group Cognitive Behavioral Therapy to Promote Weight Loss
}

\author{
Ryoko Sawamoto $^{a}$ Takehiro Nozaki ${ }^{a}$ Tomokazu Furukawa ${ }^{a}$ \\ Tokusei Tanahashi $^{a}$ Chihiro Morita ${ }^{a}$ Tomokazu Hata ${ }^{a}$ Gen Komaki ${ }^{b}$ \\ Nobuyuki Sudo ${ }^{a}$ \\ a Department of Psychosomatic Medicine, Graduate School of Medical Sciences, Kyushu \\ University, Fukuoka, Japan; bSchool of Health Sciences Fukuoka, International University of \\ Health and Welfare, Fukuoka, Japan
}

\author{
Key Words \\ Dropout · Shape concern · Parenting care · Organization
}

\begin{abstract}
Objective: To investigate predictors of dropout from a group cognitive behavioral therapy (CBT) intervention for overweight or obese women. Methods: 119 overweight and obese Japanese women aged 25-65 years who attended an outpatient weight loss intervention were followed throughout the 7-month weight loss phase. Somatic characteristics, socioeconomic status, obesity-related diseases, diet and exercise habits, and psychological variables (depression, anxiety, self-esteem, alexithymia, parenting style, perfectionism, and eating attitude) were assessed at baseline. Significant variables, extracted by univariate statistical analysis, were then used as independent variables in a stepwise multiple logistic regression analysis with dropout as the dependent variable. Results: 90 participants completed the weight loss phase, giving a dropout rate of $24.4 \%$. The multiple logistic regression analysis demonstrated that compared to completers the dropouts had significantly stronger body shape concern, tended to not have jobs, perceived their mothers to be less caring, and were more disorganized in temperament. Of all these factors, the best predictor of dropout was shape concern. Conclusion: Shape concern, job condition, parenting care, and organization predicted dropout from the group CBT weight loss intervention for overweight or obese Japanese women.
\end{abstract}


Sawamoto et al.: Predictors of Dropout by Female Obese Patients Treated with a Group Cognitive Behavioral Therapy to Promote Weight Loss

\section{Introduction}

Dropout is a serious problem in weight loss interventions for obese patients. The dropout rates vary considerably, from $10 \%$ to more than $80 \%$ depending on the type and setting of the treatment program [1-4].

Understanding the factors that contribute to dropout from weight loss programs is important for the identification of participants at high risk for dropout who can then be offered special assistance in order to increase the benefits from treatment or to find more suitable intervention options. It can also help identify patients who are highly motivated and thus most likely to benefit from the intervention $[5,6]$.

Previous studies suggest a wide range of potential predictors for dropout: demographic (age, gender, occupational status, education, socioeconomic status, financial issues, ethnicity, and travel distance), psychological and physiological health (depression, anxiety, health status, self-esteem, body dissatisfaction, social or family support, and a range of personality factors), behavioral (dieting/eating behavior, smoking, activity level and alcohol consumption), and treatment-related factors such as the type of intervention. However, a reliable and consistent set of predictors of attrition has not yet been identified $[5,6]$.

This lack of a consistent and comprehensive view of predictive factors for dropout may be partly explained by the fact that the most common approach has been to investigate single factors. Few studies have incorporated a comprehensive assessment of multiple factors in a single population study of obesity [7], although various aspects of participants have been shown to be associated with the risk of attrition in separate studies. Furthermore, some psychosocial factors such as perfectionism [8], alexthymia [9], and parental bonding style [10] have been demonstrated to be related to the prognosis of eating disorder patients; however, no previous studies have assessed the association between these factors and dropout from intervention for obese patients. By assessing not only the current psychological status, such as depression or anxiety, but also psychological traits from multiple aspects, it may be possible to gain a more profound understanding of the psychological characteristics of dropouts from weight loss intervention and the reasons for dropping out.

The aim of the present study was to investigate possible predictors of attrition by overweight or obese Japanese women participating in a group cognitive behavioral therapy (CBT) intervention from multiple aspects, including psychosocial factors, and to present a more comprehensive view of the characteristics of those who dropped out from our intervention.

\section{Material and Methods}

\section{Study Design}

This investigation was a part of a randomized controlled study that consisted of a two-phase trial that examined two strategies for maintaining weight loss, as previously reported [11]. The weight loss phase provided an intensive program of cognitive behavioral therapy for weight loss that lasted 7 months. Participants who lost at least $5 \%$ of their initial body weight during the weight loss phase were eligible for the 3-month program provided during the weight maintenance phase. In this phase, the participants were randomized to one of two weight loss maintenance interventions, with follow-up for 2 years after the end of treatment. All of the participants provided informed consent, and the Institutional Review Board of Kyushu University Hospital approved the study protocol. 
Sawamoto et al.: Predictors of Dropout by Female Obese Patients Treated with a Group Cognitive Behavioral Therapy to Promote Weight Loss

\author{
Eligibility
}

All of the participants were women aged 20-65 years with a BMI of $25 \mathrm{~kg} / \mathrm{m}^{2}$ or higher. They were able to understand and complete self-report questionnaires written in Japanese without assistance and had no physical impairment that would preclude simple exercise. Those who met the following criteria were excluded from the study: weight loss of more than $5 \mathrm{~kg}$ during the previous 6 months, current diagnosis of bulimia nervosa, past history of anorexia nervosa, current pregnancy or breast feeding, planning to become pregnant within the next 24 months, taking any form of medication that would affect body weight, suffering from any health disorder that would affect body weight, receiving nasal continuous positive airway pressure therapy for obstructive sleep apnea, currently receiving treatment for a psychiatric disorder, or planning to move within the next 10 months.

\title{
Recruitment and Entry
}

We recruited participants through a local newspaper, the university website, posters in the university hospital and hospitals near the university, and a television program. Those who were interested and potentially eligible were scheduled for an information session to learn more about the study. At the information session, the principal investigator provided the details of the study and answered questions from the participants. Those who met the eligibility criteria were enrolled in the study. After informed consent was obtained, demographic, lifestyle, and health history data were collected. Obesity-related disease was defined as hypertension, type 2 diabetes, or hyperlipidemia. Binge eating disorder was diagnosed according to the criteria of the fourth edition of the Diagnostic and Statistical Manual of Mental Disorders (DSM-IV) [12].

\section{Weight Loss Intervention}

Cooper et al. [13] originally developed this CBT program for obesity. We modified it for use in a group therapy program [14] that included the clinical guidelines on obesity of the US National Institutes of Health [15], Look AHEAD (Action for Health in Diabetes) [16], and the Diabetes Prevention Program as a framework [17]. Our treatment program was conducted in small groups of approximately 10 people. It consisted of 40 group sessions ( 30 sessions for the weight loss phase and 10 sessions for the weight maintenance phase, each lasting $90 \mathrm{~min}$ ), and 5 individual sessions over a 44 -week period. The sessions were conducted once a week for the first 34 sessions, with the remaining 6 held every other week.

Two doctors and two certified nutritionists were involved as the healthcare providers. All participants were instructed to keep a daily food diary to track their consumption of all food and drinks and to record their daily number of steps from a pedometer. They were also advised to reduce their dietary intake by 500 calories/day from their caloric intake at the beginning of therapy. The nutritionists checked the nutritional balance of the participants' diets by examining the recordings of their food intake and advised the participants about the importance of eating vegetables and reducing the consumption of fatty foods and sweets. The participants were advised to increase their level of physical exercise to a moderate intensity, such as walking 8,000-10,000 steps/day. Furthermore, a series of stress management sessions was included in the program. Dropout was defined as the participants' decision to discontinue the program without completing the full schedule of the weight loss phase.

\section{Baseline Dietary Intake, Physical Activity, and Anthropometric and Body Composition Measurement}

For baseline values, the diet and exercise logs that the participants recorded during the first week were used to calculate the mean number of calories consumed and the number of steps taken. At the entry visit, our staff measured participant height and body weight using a fully automated measuring system (Fanics MX-300, A\&D Co., Ltd., Tokyo, Japan) and also took measurements of the waist and hip. The participants used home scales to measure their body weight once a week, in the morning of the treatment session day while dressed in light indoor clothes without shoes and reported the weight at every weekly session. BMI was calculated by weight $(\mathrm{kg}) /$ height $(\mathrm{m})^{2}$. 
Sawamoto et al.: Predictors of Dropout by Female Obese Patients Treated with a Group Cognitive Behavioral Therapy to Promote Weight Loss

\section{Psychological Assessment}

All participants completed a battery of self-reported psychosocial inventories before treatment.

Depression

Depression was evaluated using the Japanese version of the Center for Epidemiologic Studies-Depression Scale (CES-D). The CES-D is a 20 -item, self-report questionnaire. The scores range from 0 to 60 , with a higher score indicating the presence of depressive symptoms [18].

Anxiety

Anxiety was evaluated using the Japanese version of the State-Trait Anxiety Inventory (STAI). The STAI is a self-report questionnaire consisting of two scales, the state and trait forms (STAI-1 assesses state anxiety and STAI-2 assesses trait anxiety). Each scale consists of 20 items that indicate the presence or absence of anxiety symptoms [19].

\section{Self-Esteem}

Self-esteem was measured using the Rosenberg Self-Esteem Scale (RSES) [20]. The scale uses a 5-point rating scale (1-5 points; range of total score, 10-50 points) with answers ranging from 'agree' to 'disagree'. The higher the total score, the greater the self-esteem (i.e. a positive attitude toward self), thereby indicating self-satisfaction. The reliability and validity of the Japanese translation of RSES has been demonstrated [21].

\section{Alexithymia}

Alexithymia was assessed by the Toronto Alexithymia Scale (TAS-20) [22]. Alexithymia has been operationalized as a multifaceted construct that includes difficulties identifying feelings, difficulties describing feelings, and an externally oriented thinking style. The TAS-20 consists of 20 items, and a higher score indicates a higher level of alexithymia. The Japanese version of the TAS-20 has shown adequate validity and reliability $[23,24]$.

\section{Parental Bonding}

The Parental Bonding Inventory (PBI) comprises two scales termed care and overprotection that measure fundamental parental styles as perceived by the child. The measure is retrospective, meaning that adults (over 16 years) complete the measure for how they remember their parents during their first 16 years. Originally, the measure was designed to be completed for mothers and fathers separately; however, in the current study the participants were instructed to complete the questionnaire only for their mother. There are 25 questions, including 12 care items and 13 overprotection items [25]. The Japanese version of the PBI has been shown to have good validity and reliability [26].

\section{Perfectionism}

Perfectionism was assessed by the Multidimensional Perfectionism Scale (MPS). The MPS is a psychometric instrument of 35 items grouped into six dimensions: i) personal standards, ii) concern over mistakes, iii) doubts about actions, iv) parental expectations, v) parental criticism, and vi) organization. A five-point Likert scale is used, ranging from 1 (strongly disagree) to 5 (strongly agree) for each item. The score for each scale was obtained by adding the corresponding items. A higher score indicates greater perfectionism. The MPS has demonstrated adequate reliability and validity [27], and the Japanese version has been validated [28].

\section{Eating Attitudes}

Eating attitude was assessed by the Eating Disorder Examination Questionnaire (EDE-Q 6.0) [29]. The 28-item EDE-Q contains 22 attitudinal questions that form four subscales (restraint, eating concern, shape concern, and weight concern). The remaining questions assess the frequency of episodes of laxative misuse, self-induced vomiting, excessive exercise, and objective binge eating episodes over the previous 28 days. 
Sawamoto et al.: Predictors of Dropout by Female Obese Patients Treated with a Group Cognitive Behavioral Therapy to Promote Weight Loss

Fig. 1. Flow diagram of partici-

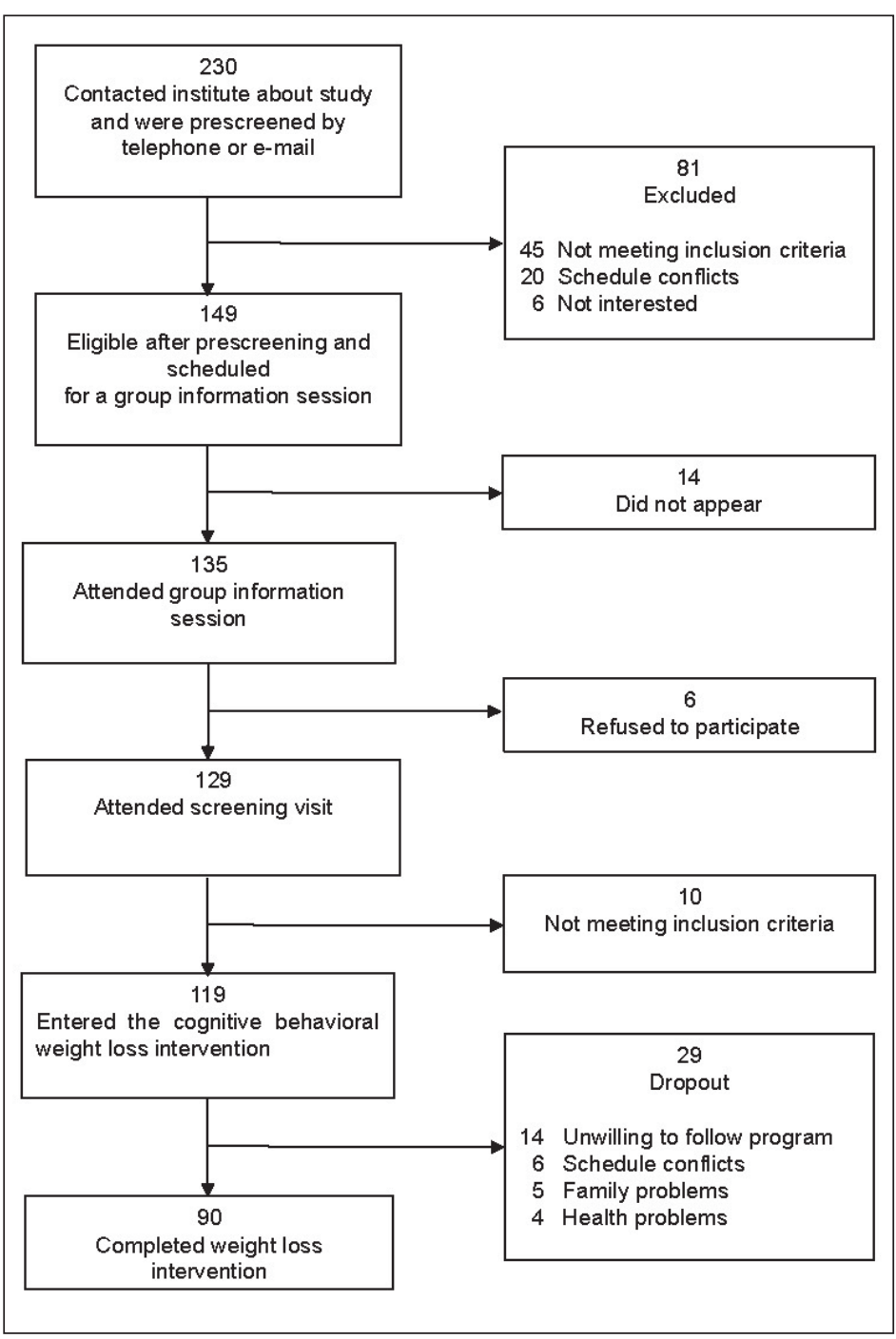
pants.

\section{Statistical Analysis}

The dropout pattern was first analyzed by comparing the baseline characteristics of the completers and non-completers. A two-sample t-test was used for comparisons between the two groups. The $\chi^{2}$ test was used to compare nominal data. The six significant and nearly significant factors in univariate analysis (job condition, history of mental disorders, TAS-difficulty identifying feelings, PBI care and EDE-Q shape concern, and MPS organization) were then examined as independent variables in a stepwise multiple logistic regression model with dropout as the dependent variable. Because the PBI overprotection and PBI care scores had a relatively high negative correlation, only the PBI care score, which was more significant than that PBI overprotection, was entered in the model in order to avoid multicollinearity. The BenjaminiHochberg procedure was used to control the false discovery rate $(\mathrm{Q})$ after multiple logistic regression: comparison was done of each individual $p$ value to a corrected $p$ value, $(i / m) Q$, where $i$ is the rank, $m$ is the total number of tests, and $Q$ is set at 0.05 . Continuous variables are expressed as the means \pm standard error (SE). A p value $<0.05$ was considered statistically significant. All statistical analyses were performed with the JMP Pro 9.0 software package (SAS Institute Inc., Cary, NC, USA). 
Sawamoto et al.: Predictors of Dropout by Female Obese Patients Treated with a Group Cognitive Behavioral Therapy to Promote Weight Loss

\section{Results}

Of the 119 participants included in the analysis, 29 (24.4\%) did not complete the 7-month weight loss phase of the intervention (fig. 1). Most dropped out in the first 3 months (18; $62.0 \%$ of the total dropouts). According to our results, the non-completers differed from the completers in the following manner (table 1): They tended to be unemployed and showed a higher rate of a past history of mental disorders. As for psychological variables, they were more alexythimic and had stronger concern about their body shape. Furthermore, noncompleters perceived their mothers to be significantly more overprotecting and significantly less caring than completers. The degree of organization (neatness) of non-completers was near significance and lower than that of completers. None of the behavioral measurements on the EDE- $Q$, such as the frequency of episodes of laxative misuse, self-induced vomiting, excessive exercise, and objective binge eating episodes, were significantly different between the completers and non-completers (data not shown).

The stepwise multiple logistic regression analysis extracted poor job condition, strong shape concern, low levels of maternal care, and low scores of organization as independent variables associated with dropout (table 2). Shape concern was the best predictor of dropout (odds ratio $(\mathrm{OR})=3.17$ ). Their significance remained unchanged even after the BenjaminiHochberg procedure.

\section{Discussion}

In the present study, the multiple logistic regression analysis demonstrated that dropouts were significantly untidier (showed lower scores of organization), had stronger body shape concern, perceived their mothers to be less caring, and tend to be jobless compared to the study completers. Of all these factors, the best predictor of dropout was shape concern.

With regard to weight/shape concerns, previous studies support our findings. Greater body dissatisfaction [7], lower body image [30, 31], and overestimation of overweight [32] were found to be associated with higher attrition. Similarly, greater weight phobia [1] and greater interference by obesity in a patient's life [2] were linked to higher attrition. These results suggest that it is important to evaluate body image before the weight loss intervention and to include CBT for improving body image into the intervention. In addition, if patients have strong body image dissatisfaction, it is important to carefully explain to them the ideal, or expected, speed of weight reduction (for our program $2 \mathrm{~kg} / \mathrm{month}$ ) and for the patients and doctors to have a common goal for weight loss intervention before starting the intervention.

As for occupational status, we found that participants who were employed were more likely to complete the treatment. This result is consistent with that of Elfhag et al. [7]. However, the majority of previous studies that evaluated the association of occupational status and attrition showed contrasting results; having jobs was one of the predictive factors for attrition $[3,4]$. Participants who are engaged in full-time jobs sometimes have difficulty in regularly attending intervention sessions or in concentrating on changing their lifestyle; therefore, it is easy to assume that they would tend to drop out from weight loss intervention. However, one interpretation of our contrasting results is that we prescreened those who were interested in the study and excluded patients who could not arrange their schedule for weekly sessions; so the participants of our study were those who decided to attend the regular sessions even though they were engaged in full-time jobs. In addition, because there is evidence that unemployment is associated with increased psychological health problems [33, 34], being engaged in a job may be related to a stable mental state and good adaptability to social life, which are considered to be important to adapting to and continuing regular group therapy. 
Sawamoto et al:: Predictors of Dropout by Female Obese Patients Treated with a Group Cognitive Behavioral Therapy to Promote Weight Loss

Table 1. Characteristics of completers and non-completers at the beginning of the weight loss intervention ${ }^{\mathrm{a}}$

\begin{tabular}{|c|c|c|c|}
\hline & Completers & Non-completers & $\mathrm{p}$ value \\
\hline Number & 90 & 29 & \\
\hline Diet history (yes $=1$, no $=0$ ) & $80.0 \%$ & $86.2 \%$ & 0.45 \\
\hline Aim of diet (health $=1$, other $=0$ ) & $71.1 \%$ & $62.1 \%$ & 0.36 \\
\hline $\begin{array}{l}\text { Somatic characteristics } \\
\text { Age, years } \\
\mathrm{BMI}, \mathrm{kg} / \mathrm{m}^{2}\end{array}$ & $\begin{array}{l}47.7 \pm 1.2 \\
31.3 \pm 0.5\end{array}$ & $\begin{array}{l}43.9 \pm 2.1 \\
32.0 \pm 0.88\end{array}$ & $\begin{array}{l}0.11 \\
0.48\end{array}$ \\
\hline $\begin{array}{l}\text { Socioeconomic status } \\
\text { Level of schooling (longer than } 12 \text { years }=1 \text {, other }=0 \text { ) } \\
\text { Job condition (worker }=1 \text {, other }=0 \text { ) } \\
\text { Marital status (married }=1 \text {, not married }=0 \text { ) }\end{array}$ & $\begin{array}{l}47.8 \% \\
58.9 \% \\
64.4 \%\end{array}$ & $\begin{array}{l}34.5 \% \\
37.9 \% \\
65.5 \%\end{array}$ & $\begin{array}{l}0.21 \\
0.049 \\
0.92\end{array}$ \\
\hline $\begin{array}{l}\text { Obesity-related diseases } \\
\text { Obesity-related disease complications } \\
\text { Binge eating disorder } \\
\text { History of mental disorders } \\
\end{array}$ & $\begin{array}{l}76.7 \% \\
9.0 \% \\
15.6 \%\end{array}$ & $\begin{array}{l}62.1 \% \\
17.2 \% \\
34.5 \% \\
\end{array}$ & $\begin{array}{l}0.12 \\
0.21 \\
0.027\end{array}$ \\
\hline $\begin{array}{l}\text { Diet and exercise habits } \\
\text { Total calorie intake per day, kcal } \\
\text { Number of walking steps per day }\end{array}$ & $\begin{array}{l}1740 \pm 50 \\
6495 \pm 304\end{array}$ & $\begin{array}{l}1738 \pm 9 \\
5694 \pm 563\end{array}$ & $\begin{array}{l}0.98 \\
0.21\end{array}$ \\
\hline $\begin{array}{l}\text { Psychological variables } \\
\text { CES-D } \\
\text { STAI-1 } \\
\text { STAI-2 } \\
\text { SES }\end{array}$ & $\begin{array}{l}11.4 \pm 0.78 \\
41.0 \pm 0.97 \\
44.1 \pm 1.2 \\
32.9 \pm 0.70\end{array}$ & $\begin{array}{l}13.8 \pm 1.4 \\
43.1 \pm 1.7 \\
44.6 \pm 2.2 \\
30.2 \pm 1.3\end{array}$ & $\begin{array}{l}0.12 \\
0.32 \\
0.86 \\
0.066\end{array}$ \\
\hline $\begin{array}{l}\text { TAS } \\
\text { Difficulty identifying feelings } \\
\text { Difficulty describing feelings } \\
\text { Externally-oriented thinking } \\
\text { PBI care } \\
\text { PBI overprotection }\end{array}$ & $\begin{array}{l}14.0 \pm 0.53 \\
14.0 \pm 0.37 \\
20.2 \pm 0.41 \\
23.5 \pm 0.88 \\
11.1 \pm 0.71\end{array}$ & $\begin{array}{l}16.4 \pm 0.98 \\
14.6 \pm 0.68 \\
20.0 \pm 0.74 \\
19.1 \pm 1.6 \\
14.1 \pm 1.3\end{array}$ & $\begin{array}{l}0.032 \\
0.49 \\
0.89 \\
0.020 \\
0.047\end{array}$ \\
\hline $\begin{array}{l}\text { MPS } \\
\text { Concern over mistakes } \\
\text { Personal standards } \\
\text { Parental expectations } \\
\text { Parental criticism } \\
\text { Doubts about actions } \\
\text { Organization }\end{array}$ & $\begin{array}{l}21.7 \pm 0.74 \\
17.1 \pm 0.52 \\
11.9 \pm 0.52 \\
8.8 \pm 0.42 \\
10.2 \pm 0.31 \\
18.7 \pm 0.44\end{array}$ & $\begin{array}{l}20.9 \pm 1.3 \\
16.6 \pm 0.95 \\
10.9 \pm 0.95 \\
10.0 \pm 0.76 \\
10.5 \pm 0.56 \\
17.2 \pm 0.80\end{array}$ & $\begin{array}{l}0.57 \\
0.64 \\
0.32 \\
0.17 \\
0.63 \\
0.058\end{array}$ \\
\hline $\begin{array}{l}\text { EDE-Q } \\
\text { Restraint } \\
\text { Eating concern } \\
\text { Shape concern } \\
\text { Weight concern }\end{array}$ & $\begin{array}{l}1.24 \pm 0.16 \\
0.68 \pm 0.10 \\
3.0 \pm 0.11 \\
2.5 \pm 0.10\end{array}$ & $\begin{array}{l}1.72 \pm 0.28 \\
0.90 \pm 0.18 \\
3.7 \pm 0.20 \\
2.9 \pm 0.18\end{array}$ & $\begin{array}{l}0.14 \\
0.30 \\
0.002 \\
0.064\end{array}$ \\
\hline
\end{tabular}

${ }^{a}$ Quantitative data are shown as means \pm SE. Qualitative data are shown as percentage. Two-sample t-test and $\chi 2$-test were used.

A new finding of our study is that a low score for maternal care, as assessed with PBI, predicted attrition. Obesity research has often focused on the relation between family structure and emotional eating. Topham et al. [35] found that parents' minimizing responses to their first-grade children's negative emotions predicted emotional eating behaviors in the children. Snoek et al. [36] found that lower levels of perceived maternal support and higher 
Sawamoto et al.: Predictors of Dropout by Female Obese Patients Treated with a Group Cognitive Behavioral Therapy to Promote Weight Loss

Table 2. Stepwise multiple logistic regression analysis with dropout as the dependent variable $^{\mathrm{a}}$

\begin{tabular}{llll}
\hline Independent variable & OR $(95 \% \mathrm{CI})$ & $\mathrm{p}$ values & $\begin{array}{l}\text { Corrected } \\
\mathrm{p} \text { value }\end{array}$ \\
\hline Shape concerns & $3.17(1.61-7.13)$ & 0.002 & 0.008 \\
Job condition & $0.17(0.04-0.59)$ & 0.005 & 0.016 \\
PBI care & $0.92(0.84-0.99)$ & 0.027 & 0.025 \\
Organization & $0.85(0.73-0.98)$ & 0.031 & 0.033 \\
\hline
\end{tabular}

a Job condition, history of mental disorders, TAS-difficulty identifying feelings, PBI-care and EDE-Q-shape concern, and MPS-organization were entered as independent variables in a stepwise multiple logistic regression model with dropout as the dependent variable. Corrected $\mathrm{p}$ values were calculated using the Benjamini-Hochberg procedure.

levels of perceived psychological and behavioral control were related to increased emotional eating in adolescents. In addition, Rommel et al. [37] demonstrated an indirect relationship between family structure and emotional eating mediated by the level of emotional awareness in obese adults. Parenting styles have also been reported to be associated with home obesogenic environments. Johnson et al. [38] found that a permissive parenting style was associated with more obesogenic environments, while an authoritative parenting style was associated with less obesogenic environments. Thus, parenting style is thought to be associated with a behavior pattern and home environment that leads to and maintains obesity. Taken together, these behavioral patterns and the home environment that patients have experienced since their childhood may influence them to easily give up continuing a challenge to improve their lifestyle.

Another major result of our study concerns the significant relation between low organization and dropout scores. This subscale assesses a person's tendency to emphasize orderliness and precision in daily tasks and their tendency to be over-organized [39]. The subscale tends not to be strongly correlated with other MPS subscales or the overall perfectionism score [27]. Rather than being a marker of psychopathology, organization appears to reflect positive personal characteristics such as achievement striving and work habits [27, 40]. There have been no previous studies of obesity that have evaluated organization as assessed by the MPS, although one study reported that organization scores assessed by the Jackson Personality Inventory (JPI) were lower in early dropouts than late dropouts in terms of behavioral self-control procedures [41]. Similarly, in our weight loss program the organization scores were lower for early dropouts (who dropped out during the first half of the weight loss phase, $n=21$ ) compared to late dropouts (who dropped out during the last half of the weight loss phase, $n=8 ; p=0.067$ ). It is easy to assume that organization (or neatness) is an important part of the temperament for maintaining adherence to the intervention, as participants were required to attend weekly sessions for the weight loss phase, to keep daily food records, and to exert control over the environment for changing their lifestyle and losing weight.

The strengths of our study are that we assessed the predictors of dropout from more aspects than have previous studies and that we demonstrated a more comprehensive view of the characteristics of the dropouts from our intervention. We also for the first time demonstrated that parental bonding style and neatness as well as body image dissatisfaction and job condition influence the vulnerability of dropouts. These characteristics illustrate why it is difficult for many people to continue the challenges related to making lifestyle changes that would help them lead a healthier life. It would be helpful to evaluate these factors before 
Sawamoto et al.: Predictors of Dropout by Female Obese Patients Treated with a

Group Cognitive Behavioral Therapy to Promote Weight Loss

starting weight loss intervention, and if new patients have high risk of dropout, we should pay careful attention to them in group therapy or propose other intervention options, such as individual therapy.

It should be noted that the present study has several limitations. First, our sample size is relatively small and we cannot apply our results to obese men because all of the participants were women. Second, our intervention was group therapy conducted in a university hospital as a clinical study; thus the setting was rather special, and it is therefore not clear that our results can be applied to weight loss interventions done in general clinical practice or to individual intervention. In future studies, it may be helpful to evaluate differences in the factors predictive of dropout from various weight loss interventions. If the predictors of dropout are different by the kind of intervention, it would allow us to assess the characteristics of our patients before intervention and to propose a suitable intervention for each patient.

In summary, the presence of stronger body shape concern, a disorganized temperament, the perception that the mother had been less caring, and not having a job predicted dropout from our CBT group weight loss intervention for overweight or obese Japanese patients. Our results suggest that multiple aspects can affect adherence to weight loss intervention; thus it is important to evaluate patients from various aspects before weight loss intervention and to offer appropriate intervention options according to individual characteristics.

\section{Acknowledgement}

This study was supported by a Research Grant (23-3) for Nervous and Mental Disorders from the Ministry of Health, Labor and Welfare of Japan, a Grant-in-Aid for Scientific Research (25460902) from the Japan Society for the Promotion of Science, and funding for a clinical research base development project (GAQQ250001) from the Ministry of Health, Labor and Welfare of Japan.

The authors thank Junko Sakaguchi and Akemi Kugimaru, national registered nutritionists, for nutritional guidance. We also thank Junji Kishimoto, Ph.D., for his contribution to the statistical analysis, and Ayako Tomihisa and Miyuki Ito for their assistance with the collection and recording of data in the registers.

\section{Disclosure Statement}

The authors declare no conflict of interest.

\section{References}

1 Dalle Grave R, Calugi S, Molinari E, Petroni ML, Bondi M, Compare A, Marchesini G; QUOVADIS Study Group: Weight loss expectations in obese patients and treatment attrition: an observational multicenter study. Obes Res 2005;13:1961-1969.

2 Bennett GA, Jones SE: Dropping out of treatment for obesity. J Psychosom Res 1986;30:567-573.

3 Inelmen EM, Toffanello ED, Enzi G, Gasparini G, Miotto F, Serqi G, Busetto L: Predictors of drop-out in overweight and obese outpatients. Int J Obes (Lond) 2005;29:122-128.

4 Huisman S, Maes S, De Gucht VJ, Chatrou M, Haak HR: Low goal ownership predicts drop-out from a weight intervention study in overweight patients with type 2 diabetes. Int J Behav Med 2010;17:176-181.

5 Moroshko I, Brennan L, O’Brien P: Predictors of dropout in weight loss interventions: a systematic review of the literature. Obes Rev 2011;12:912-934.

6 Yackobovitch-Gavan M, Steinberg DM, Endevelt R, Benyamini Y: Factors associated with dropout in a group weight-loss programme: a longitudinal investigation. J Hum Nutr Diet 2014;28(suppl 2):33-40.

7 Elfhag K, Rossner S: Initial weight loss is the best predictor for success in obesity treatment and sociodemographic liabilities increase risk for drop-out. Patient Educ Couns 2010;79:361-366.

8 Bizeul C, Sadowsky N, Rigaud D: The prognostic value of initial EDI scores in anorexia nervosa patients: a prospective follow-up study of 5-10 years. Eating Disorder Inventory. Eur Psychiatry 2001;16:232-238.

9 Pinna F, Sanna L and Carpiniello B: Alexithymia in eating disorders: therapeutic implications. Psychol Res Behav Manag 2014;8:1-15. 
Sawamoto et al.: Predictors of Dropout by Female Obese Patients Treated with a

Group Cognitive Behavioral Therapy to Promote Weight Loss

10 Bulik CM, Sullivan PF, Fear JL, Pickering A: Outcome of anorexia nervosa: eating attitudes, personality, and parental bonding. Int J Eat Disord 2000;28:139-147.

11 Sawamoto R, Nozaki T, Furukawa T, Tanahashi T, Morita C, Hata T, Komaki G, Sudo N: Higher sleep fragmentation predicts a lower magnitude of weight loss in overweight and obese women participating in a weight-loss intervention. Nutr Diabetes 2014;4:e144.

12 American Psychiatric Association: Diagnostic and Statistical Manual of Mental Disorders, 4th ed. Washington, DC, APA Press, 1994.

13 Cooper Z, Fairburn C, Hawker D: Cognitive-Behavioral Treatment of Obesity; a Clinician's Guide 2003. New York, Guilford Press, 2003.

14 Nozaki T, Sawamoto R, Sudo N: Cognitive behavioral therapy for obesity. Nihon Rinsho 2013;71:329-334.

15 Clinical Guidelines on the Identification, Evaluation, and Treatment of Overweight and Obesity in Adults - The Evidence Report. National Institutes of Health. Obes Res 1998;6(suppl 2):51S-209S.

16 Look AHEAD Research Group, Wing RR: Long-term effects of a lifestyle intervention on weight and cardiovascular risk factors in individuals with type 2 diabetes mellitus: four-year results of the Look AHEAD trial. Arch Intern Med 2010;170:1566-1575.

17 Diabetes Prevention Program (DPP) Research Group: The Diabetes Prevention Program (DPP): description of lifestyle intervention. Diabetes Care 2002;25:2165-2171.

18 Radloff L: The CES-D scale: a self-report depression scale for research in the general population. Appl Psychol Meas 1997;1:385-401.

19 Spielberger CR, Gorsuch RL, Lushene R, Vagg PR, Jacobs GA: Manual for the State-Trait Anxiety Inventory (STAI). Palo Alto, Consulting Psychologists Press, 1983.

20 Rosenberg M: Society and Adolescent Self-Image. Princeton, Princeton University Press, 1965.

21 Yamamoto M, Matsui Y, Yamanari Y: The structure of perceived aspects of self. Jpn J Educ Psychol 1982;30: 64-68.

22 Bagby RM, Taylor GJ, Parker JD: The Twenty-Item Toronto Alexithymia Scale-II. convergent, discriminant, and concurrent validity. J Psychosom Res 1994;38:33-40.

23 Komaki G, Maeda M, Arimura T, Nakata A, Shinoda H, Ogata I, Shimura M, Kawamura N, Kubo C: The reliability and factorial validity of the Japanese version of the 20-Item Toronto Alexthymia Scale (TAS-20). Jpn J Psychosom Med 2003;43:839-846.

24 Moriguchi Y, Maeda M, Igarashi T, Ishikawa T, Shoji M, Kubo C, Komaki G: Age and gender effect on alexithymia in large, Japanese community and clinical samples: a cross-validation study of the Toronto Alexithymia Scale (TAS-20). BioPsychoSoc Med 2007;1:7-7.

25 Parker GA: Parental bonding instrument. Br J Psychol 1979;52:1-10.

26 Ogawa M: The reliability and validity of the Japanese version of PBI. Jpn J Psychiatric Treatm 1991;6:1193-1201.

27 Frost R, Maten P, Lahart C, Rosenblate R: The dimensions of perfectionism. Cognit Ther Res 1990;14:449-468.

28 Tanaka H, Nagata T, Kiriike N, Kawarada Y, Matsunaga H, Yamagami S: Perfectionism in patients with eating disorders. Seishin Igaku 1999;41:847-853.

29 Fairburn C, Beglin S: Eating Disorder Examination Questionnaire (EDE-Q 6.0). New York, Guildford Press, 2008.

30 Teixeira PJ, Going SB, Houtkooper LB, Cussler EC, Metcalfe LL, Blew RM, Sardinha LB, Lohman TG: Pretreatment predictors of attrition and successful weight management in women. Int J Obes Relat Metab Disord 2004;28: 1124-1133.

31 Minniti A, Bissoli L, Di Francesco V, Fantin F, Mandragona R, Olivieri M, Fontana G, Rinaldic C, Bosello O, Zamboni M: Individual versus group therapy for obesity: comparison of dropout rate and treatment outcome. Eat Weight Disord 2007;12:161-167.

32 Collins JK, McCabe MP, Jupp JJ, Sutton JE: Body percept change in obese females after weight reduction therapy. J Clin Psychol 1983;39:507-511.

33 Eriksson T, Agerbo E, Moetensen PB, Wesgtergaard-Nielsen N: Unemployment and mental disorders. Int J Ment Health 2010;39:56-73.

34 Paul KI, Moser K: Unemployment impairs mental health: meta-analyses. J Vocat Behav 2009;74:264-282.

35 Topham GL, Hubbs-Tait L, Rutledge JM, Page MC, Kennedy TS, Shriver LH, Harrist AW: Parenting styles, parental response to child emotion, and family emotional responsiveness are related to child emotional eating. Appetite 2011;56:261-264.

36 Snoek HM, Engels RC, Janssens JM, van Strien T: Parental behaviour and adolescents' emotional eating. Appetite 2007;49:223-230.

37 Rommel D, Nandrino JL, Ducro C, Andrieux S, Delecourt F, Antoine P: Impact of emotional awareness and parental bonding on emotional eating in obese women. Appetite 2012;59:21-26.

38 Johnson R, Welk G, Saint-Maurice PF, Ihmels M: Parenting styles and home obesogenic environments. Int J Environ Res Public Health 2012;9:1411-1426.

39 Reba L, Thornton L, Tozzi F, Klump KL, Brandt H, Crawford S, Crow S, Fichter MM, Halmi KA, Johnson C, Kaplan AS, Keel P, LaVia M, Mitchell J, Strober M, Woodside DB, Rotondo A: Relationships between features associated with vomiting in purging-type eating disorders. Int J Eat Disord 2005;38:287-294.

40 Purdon C, Antony MM, Swinson RP: Psychometric properties of the Frost Multidimensional Perfectionism Scale in a clinical anxiety disorders sample. J Clin Psychol 1999;55:1271-1286.

41 Pekarik G, Blodgett C, Evans RG, Wierzbicki M: Variables related to continuance in a behavioral weight loss program. Addict Behav 1984;9:413-416. 